\title{
9. Health care cost rapid assessment post check
}

\section{PART I. BACKGROUND AND CONCEPTUAL FRAMEWORK}

Health care is considered a human right throughout the world. Therefore, it is important that a living wage includes sufficient funds for workers and their families to be able to afford adequate health care. For this reason, researchers need to do a rapid assessment of the cost of adequate health care in the study location. The preliminary estimate of NFNH cost is increased when it is found in the rapid assessment that funds included for health care in the preliminary NFNH estimate are not sufficient. Note that since this is a rapid assessment, NFNH should be increased only when there is a large difference, because rapid assessments by their very nature are only approximations.

Even in countries where government health care is free, households have out-of-pocket medical expenses. For example in many developing countries, medicines are frequently out of stock in government facilities. This requires families to purchase medicines from a private pharmacy. Furthermore, in many countries, government facilities are of poor quality and have long lines and waiting times - which can cause workers to miss work and lose pay. Getting to a government health care facility may be difficult and expensive for workers and family members. For those reasons, workers and family members in virtually all countries often go to private health care providers.

This chapter describes how to do a rapid post check for health care costs to make sure that a living wage includes sufficient funds for health care. The post check is meant to be a quick check on the cost of adequate health care for workers and their families and for this reason rapid assessment methods are used to collect information on health care costs. These include interviews and discussions with workers and key informants, and rapid inquiries of costs of services of local health providers and costs of common medicines in local pharmacies. This information is combined with secondary data on frequency of visits to various types of health care providers to get an approximate cost of adequate health care. 


\section{PART II. APPROACH TO HEALTH CARE POST CHECK}

\subsection{Key Aspects of Health Care in Location}

Health care post checks should be based on an understanding of the situation that workers face regarding health care. This includes knowledge of: (i) common health problems and illnesses in the country and location; (ii) the mix and relative importance of different types of health care providers typically used by workers and their families; (iii) quality of care especially in government facilities; and (iv) problems that workers and families have in using public and private health care such as time and distance to each of these. These factors usually differ significantly between rural and urban areas within countries. Sources of information on health, health care, health care costs, and health care systems include the Demographic Health Survey (DHS), multi-purpose household surveys, health facility surveys, health expenditure surveys, newspaper articles, and academic journal articles. Discussions with key informants are also useful including focus group discussions with workers. Every country is different and therefore it is important to lay out the context for readers and base the health care post check on the local situation.

\subsection{How to Calculate Amount Included for Health Care in Preliminary NFNH Estimate}

As indicated in Chapter 8, to estimate the amount included for health care in the preliminary estimate of NFNH costs, the percentage spent on health care relative to all NFNH expenditure is multiplied by the preliminary estimate of NFNH costs. For example, if health care expenditure was 5\% of all NFNH expenditure according to secondary data and the preliminary estimate of NFNH was $\$ 100$, then the amount included for health care in NFNH would be $\$ 5$ (i.e. $5 \% \times \$ 100$ ).

\subsection{Rapid Estimate of Cost of Adequate Health Care for a Worker and Family}

The rapid estimation of health care costs for a family is done in four steps. Each step is described in sections 9.3.1-9.3.4.

STEP 1. Determine the number of visits to different health care providers typically required per year based on secondary data.

STEP 2. Determine whether it is acceptable to expect workers to use government facilities exclusively, or whether some visits to 
pharmacies and private health care facilities are needed. When some visits to pharmacies and private facilities are needed (as is almost always the case), determine how many visits per year should be allotted to pharmacies, to private medical facilities, and to public facilities. STEP 3. Estimate amount of out-of-pocket expenses associated with a typical visit to a public facility and to a private facility and the cost for common medicines at pharmacies.

STEP 4. Calculate total cost for health care for the reference family size based on steps 1-3.

Note that rapid assessment estimates are very conservative in part because they are almost always based on typical costs of outpatient care, and so implicitly assume that in-patient care is free in government facilities.

\subsubsection{Number of visits to health care providers per year}

Information and statistics should be gathered on how frequently people visit health care providers and which type of health care providers they visit: public facility, private providers, pharmacist, etc. The Demographic and Health Survey is an excellent source for such information. Additional information can often be found from other sources such as academic journal articles and other surveys including health expenditure surveys. Based on these statistics, the number of visits to health care providers required per year by a worker and his/her family can be estimated.

In the absence of any information on frequency of illness, we suggest using 3.5 visits per person per year. This is equivalent to one visit every $3-4$ months. ${ }^{1}$

\subsubsection{Types of providers visited}

It is almost always appropriate to include funds for some visits to private providers and pharmacies, even in countries with free government facilities, as they are not always easy to access, waiting lines are often long, quality of care is often poor, and medicines are frequently out of stock. For example, in Malawi, government facilities were theoretically free, but according to workers and other key informants, government services were poor and medicines were often not available. This assessment was supported by the 2010 Malawi Demographic and Health Survey (Government of Malawi NSO and ICF Macro, 2011). For this reason, we allowed funds in our living wage estimate for workers and their families to use private health services for many of their routine visits, but not for hospitalization. In Kenya, we came to a similar conclusion and included funds for health care in private facilities for half of the required visits. 
Table 9.1 Table for estimating health care costs

\begin{tabular}{|l|l|l|l|}
\hline Type of provider & $\begin{array}{l}\text { Cost per } \\
\text { visit for } \\
\text { typical } \\
\text { illness } \\
(1)\end{array}$ & $\begin{array}{l}\text { Number of } \\
\text { visits } \\
\text { per year } \\
\text { per person } \\
(2)\end{array}$ & $\begin{array}{l}\text { Total cost } \\
\text { per year } \\
\text { for family } \\
(3)=(1) \times(2) \times \\
\text { reference family size }\end{array}$ \\
\hline Public provider & & & \\
\hline Consultation fee or co-pay & & & \\
\hline Medicine co-pay & & & \\
\hline $\begin{array}{l}\text { Medicine cost when must } \\
\text { be purchased }\end{array}$ & & & \\
\hline Lab test cost or co-pay & & & \\
\hline Private medical provider & & & \\
\hline Consultation fee & & & \\
\hline Medicine & & & \\
\hline $\begin{array}{l}\text { Laboratory test (indicate } \\
\text { how often private laboratory } \\
\text { tests are required) }\end{array}$ & & & \\
\hline Pharmacy & & & \\
\hline Medicine & & & \\
\hline Total & & \\
\hline
\end{tabular}

\subsubsection{Cost per visit to each type of health care provider}

Cost per visit should include out-of-pocket expenses such as for medicines, laboratory tests, and consultation. This cost needs to be estimated separately for public health care providers, private health care providers and pharmacists. Information on cost of a visit to a private provider and pharmacy can be found by talking to key informants, from focus group discussions with workers, and through rapid local market surveys (i.e. visiting local health care providers and pharmacists to find out typical charges for visits and medicines for common illnesses). Table 9.1 indicates the types of cost information to collect. It should be adapted to the local situation. Note that the cost for transport to and from a health care facility, although possibly substantial, is already included in transport costs.

\subsubsection{Health care cost estimate for family}

An approximate estimate of the total out-of-pocket cost per year for adequate health care for a family can be estimated by multiplying the average 
number of visits to health care providers per year for a worker and family by the typical cost per visit (based on steps 1-3 above).

Health care cost per year

$=$ \# visits per person per year to government facility

$\times$ reference family size $\times$ cost per visit

+ \# visits per person per year to private health care provider

$\times$ reference family size $\times$ cost per visit

+ \# visits per person per year to pharmacy $\times$ reference family size

$\times$ cost per visit

\subsection{Possible Adjustment to Preliminary NFNH Estimate for Health Care Costs}

The amount implicitly included for health care in the preliminary estimate of NFNH costs should be compared with the amount estimated to be needed for adequate health care in the rapid assessment. When the rapid assessment estimate of the cost of adequate health care for a worker and family is substantially greater than the amount included for health care in the preliminary NFNH estimate, NFNH should be increased. No adjustment should be made when the difference is relatively small or negative, because the rapid assessment of health care costs provides only an approximation of health care costs.

\section{PART III. EXAMPLE: RURAL MALAWI HEALTH CARE POST CHECK ${ }^{2}$}

\subsection{Amount Included for Health Care in Preliminary NFNH}

The preliminary estimate of NFNH costs for living wage for rural Malawi was K13,365 per month. Since household expenditure statistics indicated that $6 \%$ of rural NFNH expenditure was for health care, this meant that approximately K800 per family per month (i.e. $6 \%$ of K13,365), was included for health care in the preliminary estimate of NFNH.

\subsection{Rapid Estimate of Health Care Costs for Reference Family in Rural Malawi}

\subsubsection{Number of episodes of illness per year}

In Malawi, $18.4 \%$ of rural respondents reported being ill in the past two weeks according to the latest integrated household survey (IHS3). This implied approximately 4.8 episodes of illness per person per year (i.e. 
$.184 \times 26$ two-week periods), or 24 illness episodes per year for the reference size family which has 5 members.

\subsubsection{Types of illness}

Of persons who reported being ill in IHS3 (Republic of Malawi, 2012), $41.9 \%$ reported having fever and malaria, $11.0 \%$ diarrhea, $7.6 \%$ respiratory infection, $12.6 \%$ sore throat and flu, $6.6 \%$ headache, and $20.4 \%$ other. These data indicated that malaria, fever, and diarrhea were the most common illnesses.

\subsubsection{Types of health care providers visited}

Of those who reported being ill in IHS3, the vast majority sought treatment as only $6.9 \%$ did nothing, probably because the illness was not felt to be important. Of those who sought treatment, a government facility was used $54.4 \%$ of the time, while a local pharmacy and private medical facility were each used around $25 \%$ of the time (despite the fact that government facilities were free). This implied that visits to private health care providers were common, and so including funds in a living wage for such visits was reasonable and necessary.

\subsubsection{Use of private clinics and pharmacies}

Given the serious problems in accessing public health care reported by the vast majority of respondents in the 2010 Demographic and Health Survey (Government of Malawi NSO and ICF Macro, 2011) and all of the people we spoke to in Malawi, it was clearly necessary for decency for families to be able to use private clinics and pharmacies some of the time.

\subsubsection{Cost of typical health care visits and medicines}

Visits to private clinics and pharmacies in the local area and information from key informants both indicated that the consultation fee for a visit to a private clinic cost K200-300 per visit, common medicine for a bout of malaria (most common illness) cost around $\mathrm{K} 1,200$, and common medicine for dysentery (another common illness) cost around K700. Laboratory tests were commonly used during antenatal care, and for malaria, TB and HIV. Lab tests typically cost around K4,000 per test and we assumed that a lab test was required every four visits.

\subsubsection{Rapid estimate of cost of adequate health care for a worker and family}

Our rapid assessment of health care costs for a reference size family is indicated in Table 9.2. Total cost added up to around K24,600 per year for a family of five, and so to around K2,000 per month. We assumed that 
Table 9.2 Estimated health care costs example

\begin{tabular}{|c|c|c|c|}
\hline Type of provider & $\begin{array}{l}\text { Cost per visit } \\
\text { for typical } \\
\text { illness } \\
(1)\end{array}$ & $\begin{array}{l}\text { Number of } \\
\text { visits per year } \\
\text { per person } \\
\text { (2) }\end{array}$ & $\begin{array}{l}\text { Total cost per year for } \\
\text { family } \\
(3)=(1) \times(2) \times \\
\text { reference family size }\end{array}$ \\
\hline \multicolumn{4}{|l|}{ Public provider } \\
\hline Consultation fee & No cost & 2.4 & 0 \\
\hline $\begin{array}{l}\text { Medicine when } \\
\text { provided }\end{array}$ & No cost & 1.2 & 0 \\
\hline $\begin{array}{l}\text { Medicine when must } \\
\text { be purchased } \\
\text { privately }\end{array}$ & K950 & $\begin{array}{c}1.2 \\
\text { (assume medicine } \\
\text { available half the } \\
\text { time) }\end{array}$ & $\mathrm{K} 5,700$ \\
\hline $\begin{array}{l}\text { Lab test (every four } \\
\text { visits) }\end{array}$ & No cost & & \\
\hline \multicolumn{4}{|l|}{ Private clinic/doctor } \\
\hline Consultation fee & $\mathrm{K} 250$ & 1.2 & $\mathrm{~K} 1,500$ \\
\hline Medicine & K950 & 1.2 & $\mathrm{~K} 5,700$ \\
\hline $\begin{array}{l}\text { Laboratory test } \\
\text { (every four visits) }\end{array}$ & $\mathrm{K} 4,000$ & 0.3 & $\mathrm{~K} 6,000$ \\
\hline \multicolumn{4}{|l|}{ Pharmacy } \\
\hline Medicine & K950 & 1.2 & $\mathrm{~K} 5,700$ \\
\hline Total & & & $\mathrm{K} 24,600$ \\
\hline
\end{tabular}

serious illnesses and injuries were treated in government hospitals, and that 2.4 visits per person per year were to a private health care provider.

\subsection{Comparing Health Care Costs Found in Post Check with Amount Included for Health Care in Preliminary Estimate of NFNH and Adjustment}

In light of the above rapid assessment estimates of health care costs, we added K1,200 per month to our preliminary estimate of NFNH costs (i.e. approximately $\mathrm{K} 2,000$ needed minus approximately $\mathrm{K} 800$ included in preliminary NFNH estimate). 


\section{NOTES}

1. According to OECD statistics (OECD/WHO, 2012), the average number of consultations per year with doctors in OECD countries is 6.4 , which implies a visit approximately every two months (the range was from 3 to 14.6). According to CDC (Schappert and Rechsteiner, 2008), there are nearly four visits per person per year in the United States to physician offices and hospital outpatient and emergency departments, which implies a visit around every three months on average.

2. Although this example is based mainly on results of a living wage report for rural southern Malawi, assumptions and amounts have been changed for purposes of exposition. 